\title{
Reviewing Literature for Adolescents and Young Adults: Critical Pedagogy in Action?
}

\author{
Helen Nixon and Barbara Comber
}

$\mathrm{W}$

Then we were invited to co-edit a column entitled, 'Books for Adolescents', for the International Reading Association's Journal of Adolescent and Adult Literacy (JAAL), we wondered why. True, we had both been secondary school English teachers and one of us a remedial reading teacher, but what did we know about the contemporary field of children's literature? We had been transformed long since into 'literacy educators' in a tertiary institution and forever compelled to think about the serious business of literacy education rather than the pleasure (or otherwise) of children's literature. Further we had moved into popular culture and the new technologies of information and communication as the objects of new literacy practices and studies. What did the worlds of school, literacy education, tertiary education and literature reviews have to do with each other these days and did we have any place there? Was there a way that we might productively take on this role?

Perhaps there was still a yearning in both of us to have an excuse to read kids' books again or perhaps we just wanted to see what was out there. Whatever our motivation, we decided to take the job and declared our positioning in the first issue where we wrote:

As an adolescent Helen Nixon's favourite books were anything by Jane Austen and Crime and Punishment by Dostoevsky. As a young adult she worked her way through the canon of English literature as prescribed by her British influenced university. In recent years she's progressed to detective fiction and is a particular fan of Sara Paretsky. Much of her spare time at home is spent watching $\mathrm{ER}$ and lamenting the demise of Homicide: Life on the Streets. When she's out, she likes eating ltalian food and frequenting local movie theatres.

As an adolescent Barbara Comber preferred watching football and cowboy movies to reading - reading anything. However in Grade eleven her English teacher introduced her to Herman Hesse's books and she was hooked. She went on to read voraciously and became a high school English teacher where she discovered all the books she had avoided reading while she was at school were still on the syllabus. Now she reads what she finds in airport bookshops and whatever her friends and family recommend. She is particularly interested in what gets published for young adults in different places and what young readers in various locations think is 'hot'. (JAAL, September 2000, p.86)

In this article we explore an approach to the task of 'reviewing books for adolescents' which we have developed since taking over responsibility for the 'Books for Adolescents' column between September 2000 and June 2002. In particular, we explore the processes we devised for making the column a potentially 'pedagogical' text.

Reviews can be incredibly useful in selecting what to read, what to watch, where to visit, where to surf, what to buy, and what to eat. They can be helpful supplements; guide books to our everyday cultural practices. In keeping with our critical pedagogical approach to our work, we wanted to open up the practice of 'reviewing' to explore the potential forms and purposes of reviews of adolescent texts. We envisaged our editorial practices and the production of our column as forms of 'critical pedagogy'. In practice this meant that we aimed to critically reflect on our practices as editors and to encourage critical reflection in our readers.

Our approach to the task of producing the column was consistent with the vision for the Journal of Adolescent and Adult Literacy articulated by the Australian editorial team of Allan Luke and John Elkins from the University of Queensland who were in 1998 the first non-American editors of the journal. With a current readership of about 20,000 teachers and teacher educators, the journal had always provided a forum for debate about literacy teaching and learning. Under the leadership of Luke and Elkins, the journal aimed to continue to address the 'perennial problems' facing literacy educators. At the same time, it was also their goal to address:

The emergent challenges of New Times: how to train people to deal with emergent technologies and environments; how to prepare people for new forms of social participation, citizenship, consumption, and leisure; how to engage with a 
host of 'new yoices', intercultural texts, and multilingual practices in the curricula; and how to link our students' communities - real, virtual and imagined - with those of their counterparts in other cultures and worlds.

(Luke \& Elkins, JAAL, September 1998, p.6)

In an attempt to make the journal more inclusive and international, and in order to address what are global issues facing literacy educators, Luke \& Elkins 'added key literacy educators from Africa, Asia, Europe and the Americas to the editorial board and team of reviewers' (p.7). We took on the role of book review column editors at their invitation in this context of change.

From the outset we envisaged the production of the column as a political and pedagogical challenge. Underlying our work as educators is a commitment to social justice for socio-economically disadvantaged children. To us this means in part that young people will acquire literacies that serve them well by enabling them to be heard and listened to; be provided with access to the rich discursive resources of international cultures; and find satisfaction reading multiple and diverse cultural artifacts. Here's how we articulated our task, to mainly American readers, in our introductory column:

As educators from 'down under' we have long imported books from all over the globe to use with young people and are aware of the benefits of reading texts of many origins in different places. And because we are firmly committed to exploring critical and multiliteracies in practice, we hope to demonstrate how the process of reviewing might contribute to such an agenda, whilst at the same time motivating young people to read, to read widely and to interrogate the texts they read.

(JAAL, September 2000, p.86)

Thus we hoped to develop the column so that it assisted readers to explore critical reading practices with their students and to open up for debate some of the propositions put forward by recent work in the new literacy studies (Gee 2000) and multiliteracies (Cope \& Kalantzis 2000; New London Group 1996). We wanted to demonstrate by who and what we included in the column - the reviewers we decided to include and the texts that we chose to have reviewed - that literacies are culturally and socially situated practices, that texts can be read in a multiplicity of ways and that texts for adolescents and young adults are now often produced in many media, modes and interconnected webs beyond the pages of books (eg the Harry Potter ensemble). We invited reviewers to write reviews which took a critical stance - that is, we invited them to read resistantly, to contest and interrogate as well as to appreciate (Janks 1993, 2001; Luke 2000; Mellor, Patterson \& O'Neill 1987; Mellor \& Patterson forthcoming 2001). We invited young people from many different places to review contemporary texts designed for them. Often young people, while they are the intended readers, are absent from the review process. We adults and educators usually decide 'what's good for them'!

In summary, we see literacy education journals as playing an important function alongside universities and schools in helping to 'educate' prospective and current teachers about what's available, what young people are reading, and how young adult reading might productively be read and used within the curriculum. We have tried to work with the idea that the review process and review columns can operate as forms of pedagogy and as pedagogical texts for column editors and educators as well as students. In keeping with principles of critical literacy and multiliteracies, specific goals we established were: to put under scrutiny such taken-for granted categories as 'literature', 'adolescent novel' and 'young adult novel'; to include multiple reviews of the same texts; to internationalise reviewers and texts for review; and to open up the objects of reviews to multi-media texts and formats.

\section{Publishing multiple reviews of the same texts}

Our purpose in including multiple reviews of the same texts was to demonstrate that texts can be read in many different ways and that the same texts may evoke very different responses from different readers. We hoped that multiple reviews might be useful to teachers wanting to generate discussions with their students about how texts work and how readers' responses are often unpredictable and contrastive. In the column we suggested that multiple 
reviews might be shared with students before reading the published text or before discussing a text that has been read as a 'shared book' in a classroom setting. Our aim then in providing multiple reviews was to provide texts that might be used in classrooms as a catalyst to discussion and debate about response to literature but also about the politics of publishing and book consumption. In our view reviews should promote dialogue about what is educative, the contexts of reading practices and the politics of reading in schools. youth groups, community centres and homes. The production of the review column provided an opportunity to promote such dialogue.

In the course of critical reflection on our own practice, we decided to take up the challenge to work with potential teacher-reviewers and recruiters of student-reviewers in seminar situations. There we addressed questions surrounding such taken-for-granted categories as 'the review genre' and 'young adult fiction'. The critical examination of such categorizations as 'young adult' has the potential to produce useful analyses about the ways in which texts are produced and marketed for specific audiences. Accordingly we invited reviewers to explicitly consider what makes a book appropriate for and/or designed for adolescents or young adults. As editors we encouraged reviewers (of all ages) to interrogate the genres produced for adolescents, in terms of content, style, length. language. social messages, representations of relationships and to consider the question: What makes this a text for adolescent readers? What does it suggest that adolescent readers want? Because the 'Books for Adolescents' column was concerned with texts produced for adolescents and young adults, rather than including only reviews written by adults - as had previously been the case in the Journal of Adolescent and Adult Literacy - we also hoped to include reviews written by students. In order to recruit young reviewers we worked through local and international networks of educators, librarians, theorists, professional associations, teachers and friends.

The books that find their way into the hands of adolescents and young adults increasingly explore issues previously thought 'too hot to handle' in schools: sex, drugs, alcohol, gambling, racism, abuse and violence. Such 'relevant' and 'social issues' topics appear to dominate youth fiction being published at this time. As Wendy Parsons - adult reviewer and lecturer in children's literature - noted in our column, the age boundaries of reading are now very fluid, and what is obvious now is 'the power of global marketing to stretch traditional categories of what will appeal to young people' (JAAL, October 2000, p.188). We found that young people are aware of the practices of teachers, parents and publishers in matching books with people. They are aware of censorship: They are aware of the differences between books designed specifically for them (as an age group, a market) and those designed for adults or for younger children. Several 12-year-old reviewers who were very interested in the books they read nonetheless recommended that because of their controversial content, some of the books might perhaps be best given to slightly older readers than themselves. 12-year-old Kenna wrote of one book that 'I would recommend [this book] for -13-17-year-olds'. Of another book 12-year-old Cassandra wrote: 'I think this book should have been given to high school students rather than primary school students, but some primary students like me would like it' (JAAL, December 2000/January 2001, p.396). These young reviewers understood that they were complexly positioned in relation to such books. They understood that although children their age formed the 'target market' for much so-called 'realist' adolescent fiction, selection policies in their schools and the attitudes of some parents and teachers often meant that such books were not readily made available to them.

We devoted one entire 'Books for Adolescents' column to the book Jerome by William Taylor (Longacre Press 1999). For this issue we invited reviews of Jerome from high school students and young adult university students as well as teachers. We imagined that together such a set of reviews might be useful to teachers deciding whether or not to use Jerome, or which classes to use it with, given the novel's concern with such controversial topics as youth suicide and homosexuality. Such diversity of reviews, written from a range of standpoints, has the pedagogic potential to foreground for students the tensions that exist in different stakeholders' responses to the same controversial novel.

Assessments made of the novel Jerome by young female readers (aged 14 and 17) differed from those made by young male readers (aged 16 and 17). For example, 
Francesca aged 14 found Jerome to be:

an excellent book that captures the feelings and emotions of teenage death, suicide, sexuality, and friendship.... It is very realistic and shows that people react and deal with problems differently. I really liked this book and I would give it a 10 out of 10 . It's excellent!

(JAAL, September 2000, p.88)

Edward, aged 16, distanced himself from the book. In his view the main characters were:

thoughtless, cruel, selfish and arrogant. Consequently, I felt almost no sympathy for their plight ... I pretty much despised the character Marco, so I could not connect with his feelings. This was my biggest problem with the story. (p.89)

Lachlan, aged 17, judged that Jerome "lacks a sense of power, leaving the reader unmoved' ( $p .89$ ). In contrast Tom, aged 21 , argued that:

The book successfully tackles issues facing its teenage target audience. The use of e-mail and Internet technology makes the book appealing to those people familiar with these forms of communication. It also deals in a realistic and overt manner with the subjects of teen suicide, and homosexuality. Overall Jerome is confronting and contemporary and an entertaining and interesting book.

(JAAL, September 2000, p.90)

We imagined that it might prove generative in a classroom context to ask students to tease out some of the criteria for judgement that seem to underlie reviewers' positions. What literary judgments are being made? Do the different responses seem to fall out along gender or age lines? Why might this be so? If they had read the novel, students could be invited to position their own responses in relation to published reviews. Such classroom tasks would be consistent with critical literacy principles that encourage considerations of the ideological positions that texts invite readers to take up.

In an adult-produced review in the same column, Rosie
Kerin, a very experienced teacher of English, judged that:

The fast-moving episodic structure, the brevity of the text and the complex emotional terrain of sexuality, suicide, honesty, family relationships, loneliness and violence are some of the elements that would render this novel attractive to many adolescents, including those who find it difficult to locate and read fiction.

(JAAL, September 2000, p.92)

However, Kerin considered that those very same elements that might appeal to some adolescent readers were likely to be causes of concern to librarians deciding whether to purchase the novel or to teachers deciding whether to use the novel in the curriculum. Her discussion of Jerome included reflections on her own changing position about whether or not she would use the novel in an English classroom. It is our contention that there is value in making young people aware of the complexities of teachers' and librarians' positions on such matters and in inviting young people to take part in such debates. This would necessarily include consideration of what publishers take to be the 'market' for such fiction, and what school selection policies and curricula consider to be issues about adolescence and growing up that are 'appropriate' for discussion in classrooMs

Kerin's conclusion was that such dilemmas over book choice experienced by teachers and librarians indicate the need for further research and discussion that enables al! stakeholders in censorship debates to state explicit criteria for text selection for contemporary classroom use. Moreover, she suggested the value - all the while acknowledging the constraints - of teachers taking the time to become involved in exploring the value-laden nature of such terms as 'good literature', 'pornography', 'mass market fiction', 'dirty realism' and 'controversial texts'. She also suggested teachers should not try to struggle with such issues in isolation. Rather, they should work with colleagues to explore such broader sociopolitical issues as 'how we are shaped, influenced, and pressured as English teachers, and how that sometimes transforms us into moral guardians on behalf of others' (p.93).

Doctoral student in education, Mary Lou Rasmussen, 
reviewed Jerome from the clearly articulated position of an advocate of the expansion of the range of texts available for classroom discussion on the subject of teenage sexualities. She was critical of Taylor's fictional characterisations in Jerome which, in her view, tended to 'reinscribe fixed notions of sexual identity' (p.91). She also argued that:

books dealing with issues related to sexuality, especially those aimed at young people, need to move away from a focus on homophobia and youth suicide... [this emphasis] runs the risk of pathologizing these young people and has the potential to further exacerbate the difficulties they experience in relation to the exploration of sexual and gender identities.

(JAAL, September 2000, p.91).

Central to her critique was what she saw as Taylor's failure to examine the cultural conditions that hindered the book's characters from exploring their sexuality in the town where they grew up. Moreover, in her view, Taylor equated Jerome's suicide with a lack of bravery, thereby reinforcing the view that 'suicide is a personal disorder, rather than a manifestation of an inability to cope in a society that seeks to normalise heterosexuality and pathologize sexual difference' (p.92). Reviews of this kind could be particularly helpful in the context of explicating for initial and continuing teacher education students the potential of, as well as the responsibilities inherent in, bringing critical reading practices into the classroom.

\section{Internationalising reviewers and texts for review}

One aim of the 'Books for Adolescents' column was to expand the sources of books reviewed from what had formerly been mostly American publishing houses. In keeping with Luke and Elkins' aim to internationalise the journal, we aimed to review books that were internationally popular with young people and/or teachers as well as books with largely local circulation, but with potential for international readership. Accordingly we invited international publishers to submit texts for review and we sought out some smaller innovative publishing houses such as Longacre Press in New Zealand, the publishers of Jerome. Longacre Press has a small but growing list, largely devoted to adolescent and young adult readers. As part of our strategy of providing multiple reviews, we invited reviewers located in different places to explicitly consider why and how some books become international phenomena while others have mainly a local life and distribution. With what kinds of readers in what kinds of places do some books 'take off'? What do different readers in different places bring to such texts?

In two issues of the 'Books for Adolescents' column we invited reviewers across the world to consider what makes the Harry Potter books internationally popular. International perspectives on the Harry Potter novels were provided in reviews written by younger and older readers in Australia, Mexico, New Zealand, South Africa and India.

As Australians writing from their new home location in Mexico, Colin Lankshear and Michele Knobel noted that 'to date the stories have been translated into some 25 languages and have sold more than 30 million copies worldwide' (JAAL, April 2001, p.664). 'Here in Mexico City we are told that new shipments of the Potter tales in Spanish and English alike sell out practically on arrival (p.664). They judged the Harry Potter books to possess 'the bottom line literary virtues of compelling plots, sympathetic and well-developed characters, lively style, and plenty of color and texture' (p. 664) - and much more.

Reviews of the Harry Potter books by Australian father and son pair, William and Guy Louden, highlighted a 'generation gap' in relation to their perceptions of 'realism' in fiction and raised the possibility of post-colonial readings. 11 -year-old Guy Louden surprised his father by telling him that the world of Harry Potter appealed to him because the books were more 'real' than other books he had read. Reflecting on his own childhood reading experiences in the late 1950s when 'Australia was still a literary colony of Britain' (April 2001, p.668), Guy's father William wrote that for him:

\footnotetext{
Libraries were stocked with Enid Blyton's Famous Five and Secret Seven books, Captain W.E. Johns's Biggles books, and Richmal Crompton's Just William books. My reading world was soft, green, English and comfortably upper middle class.
} (JAAL, April 2001, p.668) 
In contrast, the now mature Louden acknowledges that 'real' life as it was lived was somewhat different:

In my day-to-day world, I lived in a hot dusty town in Australia's arid interior. There was nowhere to sail; the landscape was not green but brown; we lived in broad flat houses surrounded by verandas; and no one had a cook, gardener, or driver.

(p.668)

Looking back on it, this contrast between real and imagined worlds had not bothered Louden as a young reader. The fact that Biggles's natives could not possibly have been the 'natives' who lived in a camp outside his home town never crossed his mind. For the father, 'the realities of my reading world and my day-today world didn't need to overlap' (p.668). For the son, however, the 'realism' he saw in the Harry Potter tales was their primary virtue.

Ruth Nicola, a teacher-librarian at Leicester Road Elementary School in Johannesburg, South Africa, began her explanation of Harry Potter's popularity with young South African readers by pointing out that although her pupils enjoy stories with 'real' or familiar South African locales, names, and situations, the most important factors influencing their enjoyment of a book are more 'universal' literary qualities such as pace, plot and adventure. Among her students, favourite authors are Roald Dahl, Nancy Drew and Enid Blyton and they are avid readers of $R \mathrm{~L}$ Stine's Goosebumps series, Francine Pascal's Sweet Valley High books and the Babysitter's Club series. Nicola writes:

Given that most children at our school are immersed in a broadly Western, predominantly English-speaking culture, dating back to the country's colonial history, it is not surprising most of our children enjoy Harry Potter for what it is, and appear to respond to the books as do children all over the world, by marking their foreheads with lightning signs, making wizards' hats, and referring to incidents in the book in their daily conversations.

(JAAL, May 2001, pp.747-8)
Louise, a 10-year-old South African reviewer, endorses Nicola's view:

I really enjoy Harry Potter. The popularity in South Africa is unbelievable. Most of my class have read all four. If I had to compare Harry Potter with a book similar to it I'd say The Borrowers. It's got adventure; it's exciting and enjoyable.

(JAAL, May 2001, p.748)

Louise's 11-year-old classmate Zane explains how Harry Potter reached his family in the hands of visitors from the USA and in the process switched his younger brother on to reading:

I think they are very good books. My mother couldn't get my brother to read. She tried everything to make him read. Then one day two people came from America. They brought us two [Potter books]. My brother loves them. I can't say the same about me. I loved books before Harry Potter. Please make a fifth one. The books make school fun. There they got lovely teachers and awful teachers. All the work and homework: it does not just take place in school; it is school! (JAAL, May 2001, p.748)

In another part of the world, urban middle class students from Studyhall, Lucknow and St. Mary's High School, Pune in India had similar tales to tell of Harry Potter's popularity. Teacher Urvashi Sahni, who is President of the Studyhall Educational Foundation in Lucknow, noted that Harry Potter novels are particularly popular in postcolonial countries like her homeland India. Like Nicola in South Africa, Sahni in India compares the popularity of J K Rowling's work with that of the very British tales of Enid Blyton.

Students in India commented on what they saw as the 'universal' elements of the Potter books:

Kids from all over the world are reading Harry Potter because it is very imaginative and fun. On the other hand, it is so realistic since he's from an ordinary world or background, being treated like 
a slave or nobody, when he suddenly gets news that he's a wizard! And then children get so inspired by his bravery.

(Avanti, age 11,JAAL, May 2001, p.750)

Harry Potter books are adventure, mystery and fantasy all put in one. This strange mixture is what appeals to kids all over the world for kids have adventurous spirits, mysterious souls and an inclination for fantasy.

(Aradhna, age 13, JAAL, May 2001, p.750)

Children all over the world read Harry Potter because they are about murder, with strange and astonishing things.

(Suryavir, age 11, JAAL, May 2001, p.752)

These young reviewers from India also appreciated that some of their reading pleasures were derived from comparisons between their own immediate context and that of Harry Potter

Hogwarts is very different from our schools. It is amazing how you can change from a turtle to a teapot in 'Transfiguration' and the exciting spells you can cast for defending yourself in 'Defence against Dark Arts'. Teachers and parents can learn from 'Quidditch' that only studying and work and exams isn't all there is.

(Aradhna, age 13, JAAL, May 2001, p.752)

Iloved Hogwarts school. It is so cool! It feels like some school, which cannot be made true, but I wish it could be. There are a lot of ways it is like other schools I know of. There are school points for the school house, same as in our school. We have football and cricket tournaments, they have quidditch tournaments! But some things are not alike - Hogwarts school has ghosts and we don't have them. Hogwarts School teaches Dark Magic and we are taught Social Science!

(Suryavir, age 11, JAAL, May 2001, p.752)

We hadn't been sure what to expect when we invited reviewers located in different places to read the Harry Potter series of books. We were curious to understand what makes these books so popular world-wide and with both adults and children of various ages. These books which young adolescents read so voraciously appeared to be books for everyone. Yet we were interested in both the perspectives of different generations of readers and readers in different places. The adult Harry Potter reviewers drew on their literary histories to consider the appeal of Harry Potter and uncovered a shared literary canon fundamentally connected with their colonial histories. The Harry Potter books evoked strong memories of childhood reading practices in the adult reviewers. Hence Harry Potter was also read as a link in the chain of 'school' novels which depicted an essentially Anglo view of boarding school, houses and head boys; the adults reviewers read Harry Potter historically. The children also recognised both the humour and the accurate analysis of the 'school world' constructed by the author. The sorting hat, quidditch, school bullies and the oddity of the professors and their subjects serve to throw the ordinary oddities of contemporary schooling into sharp relief. Perhaps this was the 'realism' identified by some of the child reviewers. The multiple reviews produced layers of readings and insights which we hoped might generate similar conversations in classrooms internationally.

Opening up the objects of reviews to multi-media texts and formats

Because multi-media texts are increasingly a part of the cultural landscape as well as the multiliteracies of young people the world over, we were keen to invite reviews of texts that have multiple lives and appear in a variety of media - that is, the book, the film, the video, the URL, the mini-series, the electronic game, and the fast fond promotional offer. We wanted to open up for discussion the topic of the trajectories of such texts and their many manifestations and consumerist connections. In our view there is a place for exploring how some books become films and mini-series, electronic games become films, cartoons become supermarket books, and films become web-sites. As former teachers of 'literature' we are not advocating the 'death of the novel' or proclaiming the emergence of e-literatures, but we are recognizing the profound impact of multi-media on the reading practices of young people, the proliferation of sites for public pedagogies and the changing practices of 'publishers'. Our argument is that critical literacy involves reading 
across texts, looking for manifestations of new intertextual references (verbal, visual and audio), episodic narratives (where key clues may be contained in the trailer or the advertisement) cross-media apparitions and echoes. Many texts are no longer contained within the pages. And for many young people, first experiences of what are considered to be 'classic' texts and stories come through media forms other than print.

To date we have addressed these issues in a column devoted to science fiction film, The Matrix (Andy \& Larry Wachowski 1999). Young Australian doctoral student in literacy education Greg Hurrell worked with Year 11 English teacher Paul Sommer and his students to produce reviews of The Matrix from classroom assignments they had written. Hurrell found that working with media culture in the classroom can foreground for students recurring and emergent textual features, genres and styles in a range of communications media, including print literature. Hurrell wrote of the 16-year-old students that:

I was amazed at the richness and extent of their intertextual knowledge - how they were able to make far-reaching links between their viewing of The Matrix and their previous experiences with other texts. ... Their observations ranged over whole films, characters, actors, cinematic devices, genres, stylistic approaches, archetypes, linguistic features, visual motifs, theirhobbies and interests, and contemporary developments in society, linking entities as disparate as computer games and viruses with Shakespeare's plays and the Bible.

(JAAL, February 2001, p.482)

Some young people, Hurrell noted, were already tuned in to design and multi-media representational and narrative practices and techniques. In their discussions of the film these young people were drawing on 'visual literacies, spatial literacies, and furthermore, the multimodal literacies that deal with the relation and interplay among the other types of literacy' (p.482).

As Hurrell, pointed out, "the question that now faces teachers is how to respond, critically and appropriately, to this phenomenon' (p.483). As Sommer argued, there are quite conventional reasons that teachers of English might want to make the study of film central to the curriculum. From his experience:

Comparing students' analysis of The Matrix with later work in reading novels, poetry and so on, indicated that students were much more engaged and confident with film. Their analysis was noticeably more complex. There is potential, then, to use film as a model for text analysis that can be transferred to the study of a novel, rather than the other way around.

(JAAL, February 2001, p.486)

However, there are also important reasons why the teaching of new media forms alongside print literature should be considered valuable in its own right. Young people have analytic resources, developed as media users and viewers in everyday life, which may not be obvious when working with print texts, but which can be consciously mobilised by teachers seeking to build students' critical language awareness and deconstructive techniques with other media as well as books. Young people already understand humour, parody, symbolism, metaphor, characterisation, and the construction of power relations in film, television and computer game texts. The analysis of texts across media can therefore provide teachers with excellent material for positioning young people as text analysts with respect to multimedia texts as well as school books and literature.

Reviewing the reviews: what was accomplished?

Critical pedagogical practice aims to encourage people to question and challenge the status quo; to envisage how things might be different and more just; and to reflect on their own practices from this point of view. For us, this meant reflecting on what we were producing when we assembled the column. It meant talking with teachers about what really happened when they tried to work with students in critical ways around the books for review. It meant trying not to gloss over or make invisible the often complex and contradictory effects of our practices and theirs. We also had to take risks, as we had encouraged our contributors to do. Occasionally we had to send on to the editors of the journal material we thought that they, or 
those to whom they were responsible, might not fully agree with. In the same way, some teachers had to decide how to deal with quite challenging responses from young reviewers.

For one Australian teacher this included refusals from students who were refugees from wars in Eastern Europe to read books written about the situations they had experienced (JAAL, November 2001 in press). Such situations point to the complex positioning of teachers and students by publishers trying to expand their range of 'relevant' material for young readers. Our response was to publish four short pieces around this incident: a description of himself and a review written by one young refugee who read the book but refused to believe its version of events; a description of some of that same young reviewer's history written by his young adult sister who had been disturbed by his response to the book and discussed it with the teacher; and a reflection by the teacher on what had happened and the possible implications for authors and publishers. We chose to put this complicated and messy set of affairs on the public record for teachers and students rather than silence it. We hoped that it might generate further critical questioning about the practices of writing, reading and reviewing books for adolescents and young adults.

The extent to which we have been successful in our objective of making the 'Books for Adolescents' column in $J A A L$ a potentially 'critical' and 'pedagogical' text is uncertain. We would need readers' feedback to know whether we are achieving what we set out to do and whether these reviews or any aspects of our wider textual practices as column editors have been taken up by teachers and used in classrooMs However we do know something of the effects of 'being reviewers' for some of the young people and their teachers who were invited to understand reviewing as a critical pedagogical task.

A number of the elementary-aged reviewers took their books home and read them with a parent. On a number of occasions in one Australian working class school community students reported that their mothers had also read the books. The fact that these were 'new books' that the children had been invited to 'review' (as compared with reading for a school assignment) may have attracted parents' involvement or it may have been interest in the books themselves. Many of the books were about contemporary issues of everyday life - family traumas, moving, illness, sexualities and drugs. Taking the books home seemed to trigger shared reading in some households and the children and some parents were keen to do more. Where we invited parent and child pairs to review the same books, the adults reported new and valuable perceptions about their children's interpretations of the texts. They reported that they had enjoyed fruitful discussions with their children as a result of the experience and that they would like to continue the practice of reading and talking about books, particularly 'controversial' books, alongside their children.

A number of young pre-service teachers also reviewed (JAAL, November 2000). The opportunity to publish their own short reviews was new for many of them. One university lecturer reported that for one of her students, this had been a significant event in his own understanding of himself as a reader and as a writer - a real confidence builder. More than that, it had been an opportunity to explore what he knew and could say. Re-positioning the students as 'reviewers' gave them reason to read analytically and appreciatively. Repositioning teacher education students as reviewers of books intended for their future students generated critical understandings of the potential tensions between teachers' personal and professional responses to books and of the mixed assessments made by some adults of young readers' book choices.

Inviting short multiple reviews of a shared text by groups of children working with librarians and teachers also provided an occasion for talking about books, for having a say in their school site. More importantly in this context, it gave them an opportunity for speaking and writing to an international audience. As editors we were impressed by the authority with which these young reviewers and their teachers wrote. They wrote as people who knew these texts and how they worked. They wrote as readers writing to readers elsewhere. 


\section{REFERENCES}

Cope, B. \& Kalantzis, M. (eds.) (2000) Multiliteracies: Literacy Learning and the Design of Social Futures. Melbourne, Macmillan.

Gee, J. (2000) 'The new literacy studies: From "socially situated" to the work of the social', in D. Barton, M. Hamilton, \& R. Ivanic (eds) Situated Literacies: Reading and Writing in Context. London and New York: Routledge, pp. 180-196.

Janks, H. (ed) (1993) Critical Language Awareness Series. Witswatersrand University Press and Hodder \& Stoughton Educational, Johannesburg.

Luke, A. (2000) 'Critical literacy in Australia: a matter of context and standpoint', Journal of Adolescent and Adult Literacy 43, 5: 448461.

Luke, A.. \& Elkins, J. (1998) 'Reinventing literacy in "New Times", Journal of Adolescent and Adult Literacy $42,1: 4-7$.
Mellor, B., \& Patterson, A. (forthcoming 2001)

'Teaching readings', in B. Comber \& A.

Simpson (eds) Negotiating Critical

Literacies in ClassrooMs New York,

Lawrence Erlbaum.

Mellor, B., Patterson, A., \& O'Neill, M. (1987) Reading Stories. Perth, Chalkface Press.

New London Group (1996) 'A pedagogy of multiliteracies: Designing social futures', Harvard Educational Review 66, 1: 60-92.

\section{BIOGRAPHICAL NOTE}

Helen Nixon and Barbara Comber work at the Centre for Studies in Literacy, Policy and Learning Cultures at the University of South Australia. They are editors of the 'Books for Adolescents Column' in the Journal of Adolescent and Adult Literacy published by the International Reading Association. Nixon's research and teaching focuses on the integration of popular media culture and information and communications technologies into the English language and literature classroom. Comber's research interests include critical literacy and she has recently co-edited two books: Negotiating Critical Literacies in Classrooms, and Critiquing Whole Language and Classroom Inquiry. 